International Review of Research in Open and Distributed Learning Volume 18, Number 5

August - 2017

\title{
Nonnative English-Speaking Students' Lived Learning Experiences With MOOCs in a Regular College Classroom
}

\author{
Moon-Heum Cho and Moonkyoung Byun \\ Sungkyunkwan University, Seoul, S. Korea
}

\begin{abstract}
The goal of this study was to gain in-depth understanding about nonnative English-speaking students' lived experiences with massive open online courses (MOOCs) in a regular college classroom. Phenomenological methodology was used to examine those experiences in 24 Korean college students. Individual interviews, an open-ended online survey, observation notes, online weekly journal entries, and social media constituted the data sources. Findings show that students' lived experiences included (a) wonder and interest, (b) novel learning and teaching practices, (c) preference for video style, (d) learning strategies, (e) motivation to learn, and (f) need for face-to-face interaction. Implications for integrating a MOOC into a regular college course are also presented.
\end{abstract}

Keywords: MOOC, nonnative English-speaking students, MOOC integration into traditional classroom, lived experiences, college students

\section{Introduction}

The massive open online course (MOOC) has developed rapidly, drawing global attention (Saadatdoost, Sim, Jafarkarimi, \& Hee, 2015; Shah, 2015a). According to Shah (2015a), more than 35 million people around the world signed up for at least one MOOC from 2012-2016. The estimated 16-18 million people taking at least one MOOC in 2014 almost doubled in 2015.

Among the growing numbers of MOOC students are nonnative English-speaking learners. Although no official statistical data are available on their numbers, Engle, Mankoff, and Carbrey (2015) examined student characteristics accessed via Introductory Human Physiology, offered through Coursera. Among the 33,378 learners signed up for the MOOC, 15,310 students responded to the survey, 56.9\% of whom reported that English was not their first language. In addition, in Take Your Medicine: The Impact of Drug Development, a course offered through edX, 1,090 students completed open-ended writing assignments, $64.74 \%$ of whom reported themselves learners of as English as a second language (Reilly et al., 2016). In 
terms of the growing power of the internet, the number of nonnative English-speaking learners in MOOCs is expected to grow rapidly as the total number of these courses dramatically increases (Shah, 2015a).

In addition, because MOOCs have provided diverse, innovative, and high-quality content at no cost or at low cost to the public (Engle et al., 2015; Gillani \& Eynon, 2014; Jordan, 2014; Sandeen, 2013), educators from around the world have become increasingly interested in adding relevant MOOC content to their regular classrooms (Bruff, Fisher, McEwen, \& Smith, 2013; Najafi, Evans, \& Federico, 2014; Sandeen, 2013; Swigart \& Lang, 2016); yet very little empirical research has been conducted with regard to nonnative English-speaking students. The purpose of the study was, therefore, to identify nonnative English students' lived learning experiences with MOOCs in a regular college classroom.

\section{Massive Open Online Courses (MOOCs)}

Initiated by a range of prestigious universities, including Harvard, MIT, and Stanford, massive open online courses (MOOCs) have drawn substantial attention from both academia and the public (Jordan, 2014; Veletsianos, Collier, \& Schneider, 2015) and have been scrutinized to determine academic rigor whether credits earned in MOOCs can be accepted for college credits (Sandeen, 2013). Recently, leaders at six universities on three continents-North America, Australia, and Europe-planned to pilot global credits transferrable (a) to degrees and (b) among the universities in the alliance (Shah, 2016). In addition, several MOOC platforms offer credentials. For example, Udacity, Harvard, and edX offer Nanodegrees, Credentials of Readiness, and XSeries, respectively. Although the way employers recognize the credentials is unclear, more MOOC learners seem interested in acquiring certificates after completing MOOCs. For example, Johns Hopkins University made \$3.5 million in less than a year with the sale of certificates for its Data Science Specialization courses (Shah, 2015b); by implication, at least, MOOC learners recognize MOOC credentials or hope that employers recognize them as well.

Members of the general public are interested in new opportunities to acquire quality higher education content at no cost or low cost even without admission to traditional universities (Veletsianos et al., 2015). In addition, members of the media have shown interest in educational equity and have predicted changes in future higher education landscapes with MOOCs (Universities UK, 2013). With the development of diverse platforms, MOOCs have evolved in two different business models. Coursera and Udacity, led by Stanford University faculty, were developed for profit; and edX, established by MIT and Harvard and led by an MIT faculty member, was developed as a nonprofit consortium (Sandeen, 2013; Universities UK, 2013).

\section{cMOOCs vs. xMOOCs}

Two types of MOOCs are cMOOCs and xMOOCs (Sanchez-Gordon \& Luján-Mora, 2014; Universities UK, 2013). cMOOCs are situated in connectivism, in which students learn by seeking information and sharing it with other learners (Sanchez-Gordon \& Luján-Mora, 2014). In connectivism "knowledge is distributed across a network of connections, and. . learning consists of the ability to construct and traverse those networks" (Downes, 2012, para. 2). Connectivism and Connective Knowledge, the first cMOOC, organized

by Siemens and Downes from the University of Manitoba, Canada, was offered in 2008 on various blog aggregators at no cost; and almost 2,300 students enrolled in it. The course was highly interactive, social, 
nonlinear, and nonstructured, similar to online gaming (Sanchez-Gordon \& Luján-Mora, 2014). In cMOOCs students are encouraged to pursue their own learning independently by defining course content instead of depending on an instructor's guidance; their learning is not evaluated by instructors because all learners pursue different work (Hew \& Cheung, 2014).

By contrast, xMOOCs are based on a cognitivist-behaviourist approach, allowing students autonomy within the instructor's guidelines (Hew \& Cheung, 2014). Learners engage in content by watching videos developed by the instructor and completing quizzes and assignments. Often, students engage in peer evaluation for an individual project. Completed activities are used to assess student achievement. Most of the courses offered by Coursera, edX, and Udacity can be categorized as xMOOCs. These platforms offer both self-paced and structured MOOCs with course schedules. In self-paced MOOCs, learners can take a course aligned with their individual learning pace. Typically 4-8 weeks in duration, structured MOOCs with course schedules include predesigned course syllabi.

\section{Nonnative English-Speaking Participants' Learning in MOOCs}

Very little is known about how nonnative English-speaking students learn in MOOCs. Several researchers have argued that MOOC developers and educators should consider their needs. Because most MOOCs are offered in English (Shah, 2015a), the language barrier is a concern (Colas, Sloep, \& Garreta-Domingo, 2016; Reilly et al., 2016; Sanchez-Gordon \& Luján-Mora, 2014). Nonnative English-speaking students read more slowly than native speakers and are likely to play a video slowly to understand instructors' lessons (Reilly et al., 2016) and may require more time to learn the content, sometimes falling behind (Sanchez-Gordon \& Luján-Mora, 2014). Nonnative English-speaking students tend to achieve lower scores than Englishspeaking students in MOOCs (Engle et al, 2015; Reilly et al., 2016)

Another concern is nonnative English-speaking learners' participation in social interaction, such as online discussion (Colas et al., 2016). In an analysis of online forum participation in a business course offered in Coursera, Gillani and Eynon (2014) found that European and North American participants not only achieved higher grades in forum participation than those from Asia but were also more visible in online forums, participating in discussions more actively than other participants. Colas et al. (2016) have provided facilitation in online discussion in seven different languages: Bulgarian, Catalan, English, French, Greek, Slovenian, and Spanish. Although they found that such facilitation did not enhance completion rates, their study is meaningful in that they considered the needs of nonnative English-speaking learners in a MOOC delivered in English.

\section{Integrating a MOOC Into a Class}

Although global educators have shown interest in using MOOCs as teaching materials, few empirical studies have been reported. Among them, Bruff et al. (2013) researched a MOOC incorporated into a regular college classroom for 10 weeks at Vanderbilt, where a professor integrated a MOOC about machine learning, developed by Stanford University, into a face-to-face course about the same subject. Students were to complete the self-paced MOOC on the Coursera platform and submit screenshots of quizzes and assignments to the instructor, who could thus confirm their completion of the course. During the 10 weeks, students were required to attend the face-to-face class and discuss topics not covered in the MOOC. 
Students reported that they found the videos in the MOOC useful but that the content covered in the faceto-face class should have been more closely aligned with them and the subject of discussion with their instructor in the face-to-face class.

In another study, Najafi, Evans, and Federico (2014) incorporated the content of a three-week behavioural economics course from an edX MOOC into Analyzing Current Economic Issues, a five-week course designed for high school advanced placement students at a Canadian high school. Najafi et al. divided students into two groups: a MOOC-only group and a blended-mode group. The MOOC-only group had no face-to-face sessions, but the blended-mode group had an hour tutorial session with the classroom teacher. No significant differences in content knowledge were found in the two groups; however, students in the MOOConly group performed better on a written test than those in the blended-mode group. Although these two empirical studies have contributed to understanding students' learning experiences in a MOOC in the regular classroom, more empirical research on diverse students' perspectives is necessary.

\section{Driving Question}

The goal of this study was to examine nonnative English-speaking students' lived experiences when MOOCs were adopted as a learning activity in a regular college classroom.

\section{Method}

\section{Phenomenology}

We implemented phenomenological methodology to examine students' lived experiences with MOOCs in a regular college classroom. Phenomenology is an approach used to uncover the meaning of human experience as people live it (van Manen, 2007). Bruyn (1966) held that "phenomenology serves as the rationale behind efforts to understand individuals by entering into their field of perception in order to see life as these individuals see it" (p. 90). Phenomenology is not only descriptive but also entails interpretive analysis of human experience (Dowling, 2007), and a phenomenon is a moment of everyday living (van Manen, 2007). The phenomenon under study in this paper is nonnative English-speaking students' experience taking a MOOC as a learning activity in a regular college classroom. Because we aimed both at exploring and interpreting their experiences with a MOOC and because phenomenology supports descriptive and interpretative analysis, using it to address our research question was appropriate.

\section{Context of the Study}

The study was conducted in two education courses offered at a research university in South Korea: Introduction to Big Data in Education and Computer Applications in Education. For Introduction to Big Data in Education, four instructors from four different academic areas-educational technology, educational philosophy, educational administration, and educational evaluation-taught the course. As part of the learning activities, MOOC modules were integrated into the educational technology portion of the course. Students in this course took The Data Scientist's Toolbox, offered by Johns Hopkins University and 
delivered by Coursera, and were expected to learn R, a programming language used for data analysis, and expand their understanding of its application with data. Information about the MOOCs students took appears in Table 1.

Table 1

Information About the MOOCs

\begin{tabular}{llll}
\hline Regular college class & Title of MOOC & $\begin{array}{l}\text { University providing } \\
\text { the course }\end{array}$ & Duration \\
\hline $\begin{array}{l}\text { Introduction to Big } \\
\text { Data in Education }\end{array}$ & $\begin{array}{l}\text { The Data Scientist's } \\
\text { Toolbox }\end{array}$ & $\begin{array}{l}\text { Johns Hopkins } \\
\text { University }\end{array}$ & 4 weeks \\
$\begin{array}{l}\text { Computer Applications } \\
\text { in Education }\end{array}$ & $\begin{array}{l}\text { Powerful Tools for } \\
\text { Teaching and Learning: } \\
\text { Web 2.0 Tools }\end{array}$ & $\begin{array}{l}\text { University of Houston } \\
\text { System }\end{array}$ & 5 weeks \\
& $\begin{array}{l}\text { Assessment and } \\
\text { Teaching of } 21^{\text {st- }} \\
\text { Century Skills }\end{array}$ & $\begin{array}{l}\text { University of } \\
\text { Melbourne }\end{array}$ & 6 weeks \\
& & & \\
\hline
\end{tabular}

Note. All the MOOCs were offered by Coursera.org

The same instructor who taught the educational technology portion of Introduction to Big Data in Education taught Computer Applications in Education with four modules, including ePortfolio, Web 2.0, a MOOC, and global learning. Students chose one of the two following MOOCs, both offered by Coursera. Either Powerful Tools for Teaching and Learning: Web 2.0 Tools from the University of Houston System or

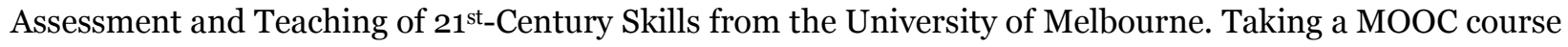
was a required class activity in the MOOC module, and students were expected to experience a new form of technology-mediated learning and develop an understanding of the influence of MOOCs on learning in school and beyond.

Because the instructor determined that students could manage the level of difficulty of the MOOC content without further explanation, he covered other relevant topics related to course content during the class time like Bruff et al. (2013). Achieving a certificate in the course was a part of the evaluation criteria for both Introduction to Big Data in Education and Computer Applications in Education, and all students earned certificates.

To support students' MOOC learning in a regular college classroom, three types of supports were provided: (a) financial support for earning a certificate of completion; (b) social learning through technology by connecting students with KakaoTalk, a social network service in Korea; and (c) weekly online journal entries.

Financial support. According to Hew and Cheung (2014), a learner's intention to achieve a certificate in a MOOC predicts the likelihood of retention; therefore, we supported students' achievement of certificates. The university where the current research was conducted provided financial support as part 
of an innovative teaching approach. Learners who ranked above the $7 \mathrm{O}^{\text {th }}$ percentile in the MOOC qualified for the certificate issued by the university offering it.

Social media. We anticipated that students would need a virtual space where they could interact with peers. Because the instructor minimized his role in MOOC learning in the regular classroom, KakaoTalk was a good social media site, where students could discuss topics, seek assistance, or provide help to others. KakaoTalk, a Korean social networking service, was chosen over Facebook or Twitter because all the Korean students had already installed it on their smartphones; students were able to chat using both written and oral text and share images or other files with one another on KakaoTalk.

Weekly online journal entries. Every Monday students received a link to weekly online journal topics created with Google Forms and were expected to complete the journal entry by Sunday. They had one week to plan, monitor, and reflect upon their learning in the MOOCs. Four prompts were provided for the weekly online entry, including the following: (a) What goals have you set for your success this week in the MOOC, and how would you evaluate your achievement? (b) Describe a challenge with your MOOC this week and the steps you took to solve the problem. (c) What feelings did you experience this week in your MOOC, and how did the emotions impact your learning? (d) If you have other ideas to share with your instructor, please describe them.

\section{Participants}

A total of 24 Korean students participated in this study at a university where their graduation requirements included the completion of four courses offered in English. All students enrolled in two courses offered in English participated in a MOOC: Introduction to Big Data in Education $(\mathrm{n}=12)$ and Computer Applications in Education $(\mathrm{n}=12)$. Students and the instructors spoke only in English during class, and students submitted all their writing assignments in English; therefore, the instructor assumed that students had no major issue taking a MOOC offered in English. Among the 24 students, the majority of students were undergraduates $(n=21)$ and less than 25 years old $(n=15)$. None of them had prior experience with MOOCs; however, most of them $(\mathrm{n}=23)$ had prior experience with an online course. Detailed demographic information about the 24 students appears in Table 2.

Table 2

Demographic Information on Participants

\begin{tabular}{|c|c|c|c|c|}
\hline Participant & Age & Gender & Status & $\begin{array}{c}\text { Number of online } \\
\text { courses taken }\end{array}$ \\
\hline \multicolumn{5}{|l|}{ The Data Scientist's Toolbox } \\
\hline 1 & 23 & Female & Undergraduate & 5 \\
\hline 2 & 21 & Female & Undergraduate & 4 \\
\hline 3 & 22 & Female & Undergraduate & 1 \\
\hline
\end{tabular}




\begin{tabular}{|c|c|c|c|c|}
\hline 4 & 26 & Male & Undergraduate & 8 \\
\hline 5 & 27 & Male & Undergraduate & 10 \\
\hline 6 & 27 & Male & Undergraduate & 7 \\
\hline 7 & 26 & Male & Undergraduate & 6 \\
\hline 8 & 24 & Female & Undergraduate & 8 \\
\hline 9 & 25 & Female & Undergraduate & 3 \\
\hline 10 & 26 & Male & Graduate & $\mathrm{O}$ \\
\hline 11 & 42 & Male & Graduate & 1 \\
\hline 12 & 34 & Female & Graduate & 11 \\
\hline \multicolumn{5}{|c|}{ Powerful Tools for Teaching and Learning: Web 2.o Tools } \\
\hline 13 & 22 & Male & Undergraduate & 15 \\
\hline 14 & 24 & Male & Undergraduate & 5 \\
\hline 15 & 24 & Female & Undergraduate & 6 \\
\hline 16 & 20 & Female & Undergraduate & 7 \\
\hline 17 & 23 & Male & Undergraduate & 4 \\
\hline 18 & 21 & Female & Undergraduate & 3 \\
\hline 19 & 21 & Male & Undergraduate & 1 \\
\hline \multicolumn{5}{|c|}{ Assessment and Teaching of $21^{\text {st_Century Skills }}$} \\
\hline 20 & 21 & Male & Undergraduate & 4 \\
\hline 21 & 23 & Male & Undergraduate & 3 \\
\hline 22 & 24 & Female & Undergraduate & 1 \\
\hline 23 & 23 & Male & Undergraduate & 6 \\
\hline 24 & 26 & Male & Undergraduate & 4 \\
\hline
\end{tabular}

\section{Data Sources}

We collected students' learning experiences from multiple data sources to validate and triangulate our findings. These multiple data sources included one-on-one interviews, an open-ended online survey, observation notes on the MOOCs, weekly online journal entries, and social interaction via KakaoTalk.

One-on-one interviews. The two researchers conducted all the interviews. Each interview lasted one hour. One of us interviewed all 12 students taking Introduction to Big Data in Education, and the other interviewed all 12 students taking Computer Applications in Education. All of the interviews were audio recorded digitally. We took notes for summary and interpretation immediately following each interview and shared notes with each other for further data analysis and discussion. Each of us transcribed all of the interviews digitally. 
Open-ended online survey. A short open-ended online survey was administered after students completed the MOOCs. The purpose of the open-ended survey was to examine students' experiences with a MOOC offered in English and their perceptions about instructional support and social interaction out of class. The survey data were downloaded into Excel files.

Observation notes. Both of us took the three MOOCs with the students to gain familiarity with the situations they mentioned in the interviews, the survey, and social interaction. We explored interfaces of the MOOCs and observed online forums, videos, and evaluation method. Then, we recorded our observations, thoughts, and interpretations in the form of notes. We did so because interpretations are best elucidated during the research process, not at its end (Rossman \& Rallis, 2003).

Weekly online learning journal entries. Weekly online journal entries were collected to examine the way students learned and engaged in a MOOC. Each student's entries were downloaded into Excel files for data analysis.

KakaoTalk messages. KakaoTalk messages exchanged were downloaded in a text file format for data analysis. The instructor was not involved in KakaoTalk messages, but students knew he could observe their conversation.

\section{Data Analysis}

Both researchers completed data analysis, which involved the five data sources interacting with one another; however, the one-one-one interviews were the primary source. These multiple data sources allowed us to develop insights into students' lived experiences with MOOCs. Data analysis was mainly conducted with the following five suggested steps (Hycner, 1999).

Bracketing and phenomenological reduction. Bracketing (or epoché) denotes the conscious resistance of a researcher to judge a phenomenon or a particular situation in terms of his or her own interests or perspectives. Instead, researchers allow human phenomena to elucidate themselves (Giorgi, 1985). Phenomenological reduction refers to the process of defining the pure essence of a phenomenon through the bracketing process. The core meaning understood through a commonly experienced phenomenon is called essence, which the researchers worked together to define after reviewing the data sets independently. For example, each of us listened to all the interviewees' audio recordings independently and repeatedly read interview transcripts line by line to gain familiarity with the words interviewees used and to develop a holistic sense of their MOOC experience in different courses as Hycner (1999) recommended. Then, each of us read research notes and social messages as well as downloaded weekly online journal entries and open-ended online survey results in Excel to define the essence of the phenomenon independently. While working together through a series of discussions, we compared our lists, revisited the transcripts if necessary, and determined the essence of the phenomenon.

Delineating units of meaning. Delineating units of meaning refers to selecting significant statements that describe a researched phenomenon. With a holistic sense of the phenomenon and essence, we worked together to extract significant statements from interview descriptions and responses to the 
online open-ended survey, and then arranged significant statements in an Excel file. In a series of discussions, we diligently examined each interview and the other data sources and retained in the Excel file only meaningful and significant statements that we agreed upon.

Clustering units of meaning to form themes. When clustering units of meaning, we grouped significant and meaningful statements that had been bracketed into themes and removed redundant statements (Moustakas, 1994), retaining the data in an Excel file. To define the pure essence of the phenomenon, we often engaged in discussion and returned to the recorded interviewed and survey data for units of meanings to make sure we agreed on the themes.

Summarizing each data set. We emailed a summary of the interview, including themes and descriptions, to each interviewee, asking each one to read carefully and determine whether the summary of the interview, themes, and descriptions accurately depicted their experience with the MOOC. We invited them to suggest any necessary revision to themes and descriptions that would more accurately represent their lived experiences, but no substantial changes were made.

\section{Identifying general and unique themes in all interviews and composite summary.} After the validity check, we scrutinized the summary and synthesized themes common to most or all participants. We also considered unique voices significant to explaining the phenomenon and defined its essence in terms of six themes, description, and interpretations as follows.

\section{Findings}

Six themes emerged from the data analysis: wonder and interest, novel learning and teaching practices in a MOOC, preference for video style, learning strategies, motivation to learn in a MOOC, and need for faceto-face interaction. Specific findings for each theme are presented below.

\section{Theme 1: Wonder and Interest}

Students felt a sense of wonder after they discovered several features, including the following: (a) MOOCs are available free of charge to anyone anywhere in the world; (b) MOOCs provide diverse professional courses that may have been unavailable had they not known about their existence; and (c) they were among many hundreds of thousands of learners who take MOOCs in over 100 countries (Jordan, 2014).

Taking an international course in Korea was a marvel to many students. Most of the students had no experience with learning in an international institution, so learning content offered from an overseas institution in English was a wonder to them. In addition, they were interested in the opportunity to interact with international students while taking a course at a university in Korea. Student 21 stated:

Taking a course offered by a prestigious international university was so wonderful. How can I [otherwise] take a course offered from the University of Melbourne while taking a regular class in 
Korea? I was so excited to take a MOOC delivered in English.

Students were also interested in new learning technology implemented in MOOCs. Because they planned to earn a certificate upon completion, they submitted to the learner identification process, which identifies enrolled learners with a webcam headshot and their typing patterns. Once students enter their headshot and typing patterns into the system, they must provide typing patterns whenever they submit a quiz and other assignments. Thus, students felt the system was trustworthy and their learning was serious. According to Student 8, "Because of the identification process, I became more serious about my learning and trusted that in a MOOC learning is serious."

\section{Theme 2: Novel Learning and Teaching Practices in a MOOC}

Taking a MOOC was a completely new experience for Korean students. For some, the online forum was new in that numerous students from different countries participated, generating countless messages. Student 22 noted, "The number of threaded messages was enormous because so many people posted so many messages. I couldn't imagine how many people participated in the online forums." Very few students in this study, however, actively took part by posting messages in the forums themselves. Most Korean students only read messages posted by others, observing the types of messages posted and how the discussions proceeded as other Asian students have done in online courses (Liu, Liu, Lee, \& Magjuka, 2010). Some students solved technical problems or issues with assignments by reading others' posts. Once students grew accustomed to teaching patterns, they paid little attention to the online forums.

One reason for Korean students' lack of participation in online forums was low confidence in their ability to write messages in English. Most students reported that their English was not good enough for communication; however, we noted many grammatical errors in messages posted in online forums by other nonnative English-speaking students from different countries. Another possible reason is that English education in Korea focuses on grammar, reading, and comprehension instead of listening, writing, and speaking as is China (Liu et al., 2010). Student 24 confirmed our interpretation, stating, "My goal was to use perfect grammar and spelling in English, but it seems other international students' goals were using English as a communication tool."

Lack of Korean students' participation in online forums was not necessarily explained with only a lack of confidence about communicating in English. Bruff et al. (2013) reported that Vanderbilt University students rarely participated in the online forums. Korean students did not feel the necessity to participate in online forums, which were not structured around course content or the creation of deep knowledge; they were still able to complete the course without interacting with others. In our observation, many international students participated in online forums; however, participation was active only during the early stages of the course and decreased over time. Most of the messages posted provided personal introductions and requests for organizing a face-to-face learning community, depending on where they lived. Even if discussions occurred with content-specific topics, most of the online discussions failed to create deep knowledge among members or lost its focus on the topics.

Korean students' interest in MOOCs led them to compare teaching styles in the MOOCs and other online 
courses they had taken in Korea. They felt that the MOOCs were more interactive than the online courses they had taken in Korea in that (a) questions about content or the assignment were answered immediately by others, including an instructor or staff member; and (b) discussions continued without the instructor's presence. Based on their experience with online courses in Korea, students stated that online instructors rarely sent messages except to announce exams or assignment due dates. Discussions were inactive if online instructors were not present even when participation was required.

\section{Theme 3: Preference for Video Style}

Video lecture is one of the main delivery formats in MOOCs. Students learned content by watching video clips of less than 15 minutes in length. Some students reported that they liked short video clips because they could watch the video lectures via mobile phone while traveling or they could use the short video clips when they had small amounts of time between classes. In addition, students reported that their engagement with video clips was high because the video clips were short. Sometimes, they downloaded video clips and replayed them when necessary.

Most students reported that a new type of video is necessary to help them engage in lectures. Our students reported that although they liked the short video clips, PowerPoint slide presentations with voiceover made engagement in learning difficult. Student 1 said, "I prefer to watch interactive video lessons. A PowerPoint slide presentation with voiceover didn't much help me engage in lessons. I would rather read a book.” In contrast to criticism of videos of PowerPoint slide presentations with voice-over, students rarely complained about video clips in which instructors' headshots were visible or multiple experts conversed onscreen.

Korean students' preferences about videos were typical. In a recent study on MOOC videos, Guo, Kim, and Rubin (2014) found that students prefer to see instructors lecturing in an informal setting. Based on their analysis, Guo et al. suggested that MOOC video producers simply film the lectures in informal settings instead of creating high-fidelity studio productions with big budgets. In addition, they found that students prefer to see the instructor write notes on the board over watching an instructor read PowerPoint slides. Their results showed that although students take courses online, they still want to have indirect interaction with the instructor on videos.

\section{Theme 4: Learning Strategies}

Students used a variety of learning strategies to understand video lectures in the MOOCs. In their early weekly journal entries, we found that they experienced high anxiety about taking an online course in English and showed low confidence in their understanding of content delivered mainly via video lectures; however, after they performed well on quizzes, they seemed more confident about understanding content and taking an online course in English.

Improved confidence can be attributed to students' successful use of diverse learning strategies in a MOOC. For example, to understand video lectures, students controlled video play speed. If the content was difficult to understand or the video required them to follow certain steps, they played the videos slowly and watched them repeatedly. In addition, they took either physical or digital notes on key words, points, or questions. 
Taking notes seemed a common learning strategy among MOOC students regardless of cultural setting. In interviews with 13 MOOC learners; 10 whose mother tongue was English; Veletsianos et al. (2015) found that taking either paper or digital notes was a primary learning strategy most students used to understand video lectures regardless of age.

Other students also used search engines, including Google or Naver, a Korean search engine, to improve their understanding of the content they learned via video clips. Many students reported that to understand concepts and address questions that arose while watching the videos, they searched the Internet for information. In addition, they reviewed notes from other regular college classes like statistics to understand concepts presented in the video lectures.

Furthermore, students engaged in both physical and virtual interactions with classmates taking the same MOOC in a regular classroom. One student reported that she learned of the existence of a script for each video by interacting face-to-face with her Korean classmates. Some engaged in virtual interaction when they sought assistance through KakaoTalk and received immediate help installing the $\mathrm{R}$ program, confirming the use of social media for support. An example is presented in the following exchange:

[Student 3] [9:15 a.m.] I found a different R program on the website, which is different from what we watched in the video lecture. I guess the one on the website is an upgraded program. Can I download this?

[Student 2] [9:36 a.m.] I guess so. I also downloaded the new one.

[Student 3] [9:39 a.m.] I can’t activate the R program. I reinstalled it, but strange windows keep popping up.

[Student 2] [9:45 a.m.] Can you remove the installed R program and reinstall it?

\section{Theme 5: Motivation to Learn in a MOOC}

Students showed diverse motivation while taking a MOOC. Some were very interested in achieving a certificate issued by an internationally recognized university while taking a course in Korea. Most of them had no experience with an international institution, so learning content offered by an overseas institution in English gave them the prestige associated with taking an international course without physically traveling to a foreign university. Student 5 stated, "I worked hard even during the weekend because of the certificate issued from a famous international institution."

Students who were more interested in achieving a particular grade or passing the regular college course were not fully engaged in the MOOC. Disinclined to explore new features of the MOOCs, some of them knew the instructor read weekly journals and monitored KakaoTalk; therefore, they wrote weekly journals to show him that they were working hard or interacting well with others. Those students thought the activities 
designed by the instructor were not particularly helpful to their success and completed them only to achieve a good grade.

The other type of student we observed among MOOC learners tended to enjoy learning content via the MOOC even though it was a required activity in a regular college classroom. These students appreciated the opportunity to learn content in a new way and tended to master it; they effectively used weekly journal entries and KakaoTalk as means to improve their learning process and to acquire information or assistance from classmates. In addition, these students reported improving their English by taking the MOOCs and observing the active learning patterns of international students, which challenged them to change their own learning practices.

\section{Theme 6: Need for Face-to-Face Interaction}

Students desired more face-to-face interaction with the instructor in the regular classroom, and many of them mentioned the necessity of very structured and detailed guidance before taking a MOOC; for example, students wanted the college classroom instructor to provide an overview of the interface of the MOOC and explain in detail the functions of each menu. Because the design of the MOOC and presentation of materials online were quite different from their previous online experience, some students reported that they had difficulty locating the materials and assignments. Several students requested that the instructor demonstrate how to navigate the MOOC.

Valuing interaction in the physical classroom, students also preferred face-to-face meetings with classmates in a regular classroom and often wanted immediate feedback from peers to verify that they were on the right track like any other online student. They seemed to seek comfort about their learning by observing and interacting with classmates. Although social media were helpful in acquiring assistance from others, students still wanted face-to-face sessions. Combining physical classroom meetings and social media may enhance students' learning experiences.

Students wanted classroom instructors to be more directly involved in their learning process; for example, some wanted the instructor to review video lectures with them because they wanted to make sure they understood the content correctly. Others suggested that the entire class watch the video lectures together and discuss the content in face-to-face classroom sessions. Student 16 said:

I didn't realize that I rely so heavily on others for learning. Watching a video alone was a new experience with me, which I rarely did. I always studied with others. Even for online learning I did a group study. I would suggest we watch the videos and study together.

\section{Discussion}

The purpose of this study was to gain in-depth understanding of the lived learning experience of nonnative English-speaking students, specifically Koreans, with MOOCs in a regular college classroom; and we found that learning in a MOOC challenged many of them. Not only issues with English but also teaching and 
learning practices different from their previous experience caused some reluctance to take a MOOC independently with minimum instructor support; however, some highly motivated students showed strong interest in taking more MOOCs for professional development and to achieve more of their own goals.

We also found that students preferred face-to-face sessions led by an instructor, who invited them to participate either in large- or small-group discussion. Similar results were reported with students at Vanderbilt University (Bruff et al., 2013). This can be explained in at least two ways. First, the content students learned was unfamiliar, so their anxiety about understanding might have been high; and they might have wanted someone with authority in content to lead their learning like an instructor in a traditional classroom. Such anxiety seems a common concern regardless of language. For example, reliance on authority to check the validity of their understanding was evident among Chinese students taking an online MBA with American students (Liu et al., 2010). In addition, the concern of college students in Switzerland about understanding French MOOC content without instructor presence was also reported (Li et al., 2014).

Second, because all the MOOC materials, including video lectures, were delivered in English, Korean students wanted to check their level of content understanding immediately through synchronous social interaction. One Korean student suggested watching MOOC video lectures with study group members to enhance their learning experience. Li et al. (2014) compared two types of MOOC study group formats: One involved watching MOOC videos with study group members and interacting with them; the other, individual watching. They found that college students in Switzerland perceived the study group format as a more positive learning experience, characterized by greater attentiveness and engagement through synchronous social interaction than watching MOOC videos individually.

Taking a MOOC allowed nonnative English-speaking students to experience different learning and teaching practices online (Liu et al., 2014). Most Korean participants in the current study had previous online learning experience. Although diverse forms of online courses exist in Korea, we found that most of the online courses students took were self-paced online lectures, designed to teach certain content without social interaction. These courses differ from generic online courses emphasizing high-level human interaction. In these courses students simply access the online courses and learn the content by watching videos; therefore, these Korean students rarely saw discussion boards developed through interaction without instructor presence. For Korean students, other students' voluntary interactions, such as seeking assistance and providing help by replying or posting YouTube learning materials, were novel to them. Korean students' experience with a MOOC gave them new perspectives on teaching and learning practices online and may have given them an opportunity to reflect upon their participation as students in MOOCs. Although these new experiences challenged them, they may have helped the students learn in various MOOCs offered in English as more nonnative English-speaking students enroll in them for different reasons (Jordan, 2014).

We found that MOOCs have considerable potential as learning materials in a classroom of nonnative speakers of English, as other educators have (Bruff et al., 2013; Najafi et al., 2014). Our recommendations for instructors planning or considering using a MOOC offered in English as a part of classroom activities 
for students whose first language is not English appear below. First, after completing an analysis of students' learning needs, a thorough orientation should be conducted in the college classroom (Cho, 2012). Researchers have found that the quality of orientation to the MOOC affected online students' retention rates (Glazer \& Murphy, 2015). In this study, we provided orientation focused on how to sign up and enroll in a MOOC; however, our students wanted to have more detailed orientation. Specifically, they wanted the instructor to teach them how to navigate MOOCs and how to learn in them. We suggest that in the orientation, either the classroom instructor or a MOOC developer should inform students unfamiliar with teaching and learning practices in MOOCs offered by U.S. institutions about the way they will be taught and what will be expected of them.

Second, the flipped classroom approach in which students watch video content at home and spend a portion of class time in discussion can be an alternative to help students learn in a MOOC (Israel, 2015; Li et al., 2014; Sandeen, 2013; Swigart \& Liang, 2016). We found many students wanted confirmation of their understanding from an instructor even if they had achieved high scores on quizzes. Students were unable to tolerate uncertainty. In the flipped classroom in which students engage in social interaction with instructors or peers, we expect students will engage more in learning with less concern about their understanding of content through immediate social interaction (Israel, 2015; Li et al., 2014).

Third, an instructor can increase MOOC completion rates without providing the financial support needed for students to attain certificates when the MOOC is used as a learning activity. If the instructor has a teaching grant as we did, providing financial support to students to earn certificates is feasible; however, the certificates cost money and grants are not always available. We found that even for extrinsically motivated students, earning a good grade is more important than achieving a certificate; therefore, requiring participation in a MOOC itself can facilitate its completion. If instructors want to see student participation in a MOOC, they can still monitor students' progress by asking them to submit screenshots demonstrating their learning progress as Bruff et al. (2013) did with their students.

\section{Significance of the Study}

Although examining nonnative English-speaking students' learning experiences with MOOCs in English is important, very little empirical research has been conducted to investigate them. This study is meaningful in that we explored nonnative English-speaking students' lived experience. The results are not only useful for MOOC development and operation but also contribute to the body of MOOC literature.

Veletsianos et al. (2015) noted that most current MOOC studies have dealt with demographic information, patterns of participation, and completion or dropout rates based on self-reported surveys or large systemgenerated data sets. They called for more empirical studies examining learners' voices with various data sources to determine why they do what they do and how they do it in MOOCs. Compared to most MOOC studies in which researchers used secondary data or survey data that may restrict understanding of MOOC learners (Veletsianos \& Shepherdson, 2016), our study was unique in that we used multiple data collection methods, such as interviews, surveys, observations, and learning journals not often used in MOOC studies to examine students' lived experiences to examine students' lived experiences. 


\section{Conclusion}

As more nonnative English speakers are expected to take MOOCs offered in English, additional consideration is necessary. In our study, we pointed out that language is a barrier that can hinder nonnative English speaking students' active participation in a MOOC; however, other issues related to teaching and learning practices that differ from nonnative English-speaking students' experiences should be considered cautiously. We call for more empirical research that explores nonnative English-speaking students' lived experiences in MOOCs. In future research, not only their levels of English proficiency but also their prior experiences with MOOCs offered in English should be considered. Conducting these empirical studies is critical as more universities, such as University of Pennsylvania and University of California-Irvine offer MOOCs solely for nonnative English-speaking students.

\section{References}

Bruff, D. O., Fisher, D. H., McEwen, K. E., \& Smith, B. E. (2013). Wrapping a MOOC: Student perceptions of an experiment in blended learning. MERLOT Journal of Online Learning and Teaching, 9(2), 187-199.

Bruyn, S. T. (1966). The human perspective in sociology: The methodology of participant observation. Upper Saddle River, NJ: Prentice-Hall.

Cho, M.-H. (2012). Online student orientation in higher education: A developmental study. Educational Technology Research \& Development, 6o(6), 1051-1069.

Colas, J.-F., Sloep, P. B., \& Garreta-Domingo, M. (2016). The effect of multilingual facilitation on active participation in MOOCs. International Review of Research in Open and Distributed Learning, $17(4), 280-314$.

Dowling, M. (2007). From Husserl to van Manen. A review of different phenomenological approaches. International Journal of Nursing Studies, 44, 131-142.

Downes, S. (2012, May 21). Connectivism and connective knowledge. [Web log post]. Retrieved from http://www.downes.ca/post/58207

Engle, D., Mankoff, C., \& Carbrey, J. (2015). Coursera's instructor human physiology course: Factors that characterize successful completion of a MOOC. International Review of Research in Open and 
Distributed Learning, 16(2), 46-68.

Gillani, N., \& Eynon, R. (2014). Communication patterns in massive open online course. Internet and Higher Education, 23, 18-26.

Giorgi, A. (1985). Phenomenology and psychological research. Pittsburgh, PA: Duquesne University Press.

Glazer, H. R., \& Murphy, J. A. (2015). Optimizing success: A model for persistence in online education. The American Journal of Distance Education, 29, 135-144.

Guo, P., Kim, J., \& Rubin, R. (2014). How video production affects student engagement: An empirical study of MOOC videos. In Proceedings of the first ACM conference on Learning @ scale (pp. 4150). Atlanta, GA: ACM.

Hew, K. F., \& Cheung, W. S. (2014). Students' and instructors' use of massive open online courses (MOOCs): Motivations and challenges. Educational Research Review, 12, 45-58.

Hycner, R. H. (1999). Some guidelines for the phenomenological analysis of interview data. In A. Bryman \& R. G. Burgess (Eds.), Qualitative research (Vol. 3, pp. 143-164). London, UK: Sage.

Israel, M. J. (2015). Effectiveness of integrating MOOCs in traditional classrooms for undergraduate students. International Review of Research in Open and Distributed Learning, 16(5), 102-118.

Jordan, K. (2014). Initial trends in enrolment and completion of massive open online courses. The International Review of Research in Open and Distance Learning, 15(1), 133-160.

Li, N., Verma, H., Skevi, A., Zufferey, G., Blom, J., \& Dillenbourg, P. (2014). Watching MOOCs together: Investigating co-located MOOC study groups. Distance Education, 35(2), 217-233.

Liu, X., Liu, S., Lee, S-H., \& Magjuka, R. J. (2010). Cultural differences in online learning: International student perceptions. Educational Technology \& Society, 13(3), 177-188.

Moustakas, C. (1994). Phenomenological research methods. Thousand Oaks, CA: Sage.

Najafi, H., Evans, R., \& Federico, C. (2014). MOOC integration into secondary school courses. The International Review of Research in Open and Distance Learning, 15(5), 306-322.

Reilly, E. D., Williams, K. M., Stafford, R. E., Corliss, S. B., Walkow, J. C., \& Kidwell, D. K. (2016). Global times call for global measures: Investigating automated essay scoring in linguistically diverse MOOCs. Online Learning, 2O(2), 97-109.

Rossman, G., \& Rallis, S. F. (2003). Learning in the field: An introduction to qualitative research. Thousand Oaks, CA: Sage. 
Saadatdoost, R., Sim, A. T. H., Jafarkarimi, H., \& Hee, J. M. (2015). Exploring MOOC from education and information systems perspectives: A short literature review. Educational Review, 67(4), 505-518.

Sanchez-Gordon, S., \& Luján-Mora, S. (2014). MOOCs gone wild. Proceedings of the 8th International Technology Education and Development Conference INTED, Valencia, Spain, 1449-1458.

Sandeen, C. (2013). Integrating MOOCs into traditional higher education: The emerging MOOC 3.0 era. Change: The Magazine of Higher Learning, 45(6), 34-39.

Shah, D. (2015a, December 21). By the numbers: MOOCs in 2015. Retrieved from https://www.classcentral.com/report/moocs-2015-stats/

Shah, D. (2015b, December 23). MOOC trends in 2015: Big MOOC providers find their business models. Retrieved from https://www.class-central.com/report/mooc-business-model/

Shah, D. (2016, January 12). Six universities in talks to pilot credits for MOOCs. Retrieved from https://www.class-central.com/report/moocs-global-credit-transfer/

Swigart, V., \& Liang, Z. (2016). Digital resources for nursing education: Open courseware and massive open online courses. International Journal of Nursing Science, 3, 307-313.

Universities UK. (2013). Massive open online courses: Higher education's digital moment? London, England: Author. Retrieved from http://www.universitiesuk.ac.uk/ highereducation/Documents/2013/MassiveOpenOnlineCourses.pdf

van Manen, M. (2007). Phenomenology of practice. Phenomenology \& Practice, 1(1), 11-30.

Veletsianos, G., Collier, A., \& Schneider, E. (2015). Digging deeper into learners' experiences in MOOCs: Participation in social networks outside of MOOCs, note taking and contexts surrounding content consumption. British Journal of Educational Technology, 46(3), 570-587.

Veletsianos, G., \& Shepherdson, P. (2016). A systematic analysis and synthesis of the empirical MOOC literature published in 2013-2015. International Review of Research in Open and Distributed Learning, 17(2), 198-221.

\section{Athabasca} University

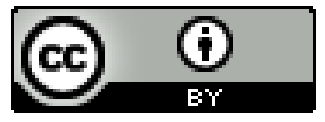

